\title{
FAKTOR-FAKTOR YANG MEMPENGARUHI KUALITAS PELAYANAN PERPUSTAKAAN SMAN 6 KOTA TANGERANG SELATAN DENGAN MENGGUNAKAN METODE ANALISIS FAKTOR
}

\author{
Aditama $^{1 *}$, Usep Rahmat ${ }^{2}$, dan Choirul Basir ${ }^{3}$ \\ ${ }^{1,2,3}$ Program Studi Matematika, FMIPA-Universitas Pamulang \\ "Email: dosen00052@unpam.ac.id
}

\begin{abstract}
The factors that can affect service quality on costomer satisfaction can be formed from the reduction process. In this study, researches will examine the conditons that exist in the library of Senior High School 6 of South Tangerang which is in the Cluster Pamulang Permai 1 Pamulang South Tangerang Banten. The method to be used is the Factor Analysis method with the principal component analysis technique using SPSS 22 software. There are several dimensions of servise quality that can affect consumer behavior, namely: showing that consumer perceptions of servise quality include perceptions related to physical facilities (Tangibles), reliability, responsiveness, assurance, and empathy which can be measured by the SERVQUAL instrument (Parasuraman, 1988). The measurement result with these instruments provide information about how far the services provided can meet customer satisfaction expectations. The population in the study were students who borrowed books at the library of Senior High School 6 of South Tangerang and the research sample was 100. So by using the factor analysis method through the SPSS application it is known that the factors that affect the level of consumer satisfaction with the quality in the library service of Senior High School 6 of South Tangerang is tangible factor, a reliability, an empthy, and assurance with each correlation value of 0.725; 0.502; 0.618; 0.850. So that guarantee factor is the factor that most influences the level of library service quality.

Keywords: Factor Analysis, Service Quality, Consumer Satisfaction, Principal Component Analysis
\end{abstract}

\begin{abstract}
ABSTRAK
Faktor-faktor yang bisa mempengaruhi kualitas pelayanan terhadap kepuasan pelanggan dapat terbentuk dari proses reduksi berbagai faktor. Dalam penelitian ini, peneliti akan meneliti kondisi yang ada pada Perpustakaan SMA Negeri 6 Kota Tangerang Selatan yang ada di Komplek Pamulang Permai 1 Pamulang Tangerang Selatan Banten. Metode yang akan digunakan adalah metode Analisis Faktor dengan teknik Principal Component Analysis menggunakan software SPSS 22. Ada beberapa dimensi kualitas pelayanan yang dapat mempengaruhi perilaku pelanggan dengan melakukan pengukuran menggunakan instrument SERVQUAL terhadap persepsi pelanggan pada kualitas Tangibles, Reliability, Responsiveness, Assurance, dan Emphaty (Parasuraman, 1988). Pengukuran tersebut selanjutnya akan memberikan penilaian seberapa memuaskan tingkat pelayanan tersebut sesuai harapan pelanggan. Populasi dalam penelitian adalah siswa yang melakukan peminjaman buku di Perpustakaan SMAN 6 Kota Tangerang Selatan dan untuk sampel penelitiannya berjumlah 100. Maka dengan menggunakan metode analisis faktor melalui aplikasi SPSS diketahui bahwa faktor-faktor yang mempengaruhi tingkat kepuasan pelanggan terhadap kualitas pelayanan Perpustakaan SMAN 6 Kota Tangerang Selatan adalah faktor sarana fisik, kehandalan, empati, dan jaminan dengan nilai korelasi masingmasing sebesar 0,$725 ; 0,502 ; 0,618 ; 0,850$. Sehingga faktor Assurance merupakan faktor yang paling mempengaruhi tingkat kepuasan pelanggan pada layanan perpustakaan.
\end{abstract}


Kata kunci: Analisis Faktor, Kualitas Pelayanan, Kepuasan Pelanggan, Principal Component Analysis

\section{PENDAHULUAN}

Kepuasan pelanggan dalam hal ini anggota perpustakaan sangatlah dipengaruhi oleh pelayanan dan kualitas buku-buku yang tersedia di perpustakaan (Sudarno, 2015). Dalam penelitian ini, peneliti akan meneliti kondisi yang ada pada Perpustakaan SMA Negeri 6 Kota Tangerang Selatan, yang ada di Komplek Pamulang permai 1 Pamulang Tangerang Selatan Banten. Perpustakaan adalah perpustakaan milik sekolah yang fasilitasnya kebanyakan didanai oleh dana pemerintah, dalam hal ini ada anggaran khusus dari dana Bantuan operasi sekolah yang disebut BOS. Dana yang dialokasikan untuk pembelian buku setiap tahunnya sekitar 20\% dari anggaran dana BOS yang diterima sekolah tersebut. Perpustakaan sekolah juga mendapat bantuan dari perpustakaan daerah yang berupa pelatihan bagi petugas perpustakaan serta pemberian buku-buku bacaan yang berupa buku cerita biasanya diberikan tiap awal tahun.

Jumlah siswa yang menjadi anggota perpustakaan di SMA Negeri 6 Kota Tangerang Selatan berjumlah 1138 siswa yang terdiri dari siswa kelas X sebayak 423 orang, kelas XI sebanyak 362, dan siswa kelas XII sebanyak 353 siswa, jumlah rombongan belajar yang ada sejumlah 31 rombel yang terdiri kelas $\mathrm{X}$ sebanyak 11 rombel, kelas XI sebanyak 10 rombel dan kelas XII sebanyak 10 rombel. Karena jumlah peserta didik yang cukup banyak maka perpustakaan yang ada harus bisa melayani seluruh siswanya terutama dalam hal pemenuhan buku wajib yang harus dimiliki oleh siswa, disamping buku wajib tentunya juga tidak kalah pentingnya buku penunjang. Perpustakaan SMA Negeri 6 Kota Tangerang Selatan telah berbenah diri dalam pelayanan kepada pelanggan dengan menyediaakan buku-buku bacaan berkualitas dilengkapi pula fasilitas penunjang seperti ruangan yang ber AC, tempat baca baik berupa karpet maupun meja belajar.

\section{METODOLOGI}

\subsection{Tempat dan Waktu Penelitian}

Penelitian ini di laksanakan di Perpustakaan SMA Negeri 6 Kota Tangerang Selatan, Komplek Perumahan Pamulang Permai 1, Pamulang, Tangerang Selatan, yang dimulai tanggal 03 Februari 2020 sampai 29 Maret 2020 .

\subsection{Populasi dan Sampel}

Populasi merupakan keseluruhan (universum) dari obyek penelitian yang dapat berupa manusia, hewan, tumbuh-tumbuhan, udara, gejala, nilai, peristiwa, sikap hidup, dan sebagainya, sehingga obyek-obyek ini dapat menjadi sumber data penelitian (Bungin, 2013). Populasi yang dimaksud disini adalah siswa SMA Negeri 6 Kota Tangerang Selatan yang menjadi anggota perpustakaan di Perpustakaan SMA Negeri 6 Kota Tangerang Selatan. Sampel adalah bagian dari jumlah dan karakteristik yang dimiliki oleh populasi tersebut (Sugiyono, 2016). Jadi sampel penelitian adalah obyek yang dilibatkan langsung dalam penelitian sesungguhnya yang dapat menjadi wakil dari populasi (Nazir, 2016). Dari sampel yang diambil pada tanggal 03 Februari 2020 sampai 29 Maret 2020 peneliti melakukan uji kuesioner sebanyak 100 pelanggan. 


\subsection{Pengambilan Sampel}

Teknik Pengambilan sampel menggunakan sampling insidental. Sampling insidental adalah teknik penentuan sampel berdasarkan kebetulan, yaitu siapa saja yang secara kebetulan/incidental bertemu dengan peneliti dapat digunakan sebagai sampel, bila dipandang orang yang kebetulan ditemui itu cocok sebagai sumber data (Sugiyono, 2016).

\subsection{Jenis Data Penelitian}

Pada penelitian ini data yang dipakai adalah data primer. Data primer adalah data yang diperoleh langsung dari sumbernya, diamati dan dicatat untuk pertama kalinya (Sangaji Mamang, 2015). Data primer pada penelitian ini diperoleh menggunakan survey dengan alat ukur berupa kuesioner yang diberikan secara langsung kepada pelanggan yang berkunjung ke Perpustakaan SMA Negeri 6 Kota Tangerang Selatan yang diambil sebagai sampel penelitian.

\subsection{Pengumpulan Data}

Untuk memperoleh data secara terperinci dan baik, maka peneliti melakukan observasi sendiri di lapangan dengan alat ukur kuesioner. Kuesioner adalah teknik pengumpulan data suatu daftar yang berisi serangkaian pertanyaan tertulis yang disusun secara sistematis, yang diserahkan langsung kepada responden yang akan diteliti untuk diisi (Gunawan, 2016). Kuesioner merupakan alat untuk mewawancarai orang. Sebuah kuesioner memberikan suatu kerangka dimana pewawancara dapat mencatat jawaban, tanpa kuesioner wawancara tidak akan teratur (Yeri Sutopo, 2017). Data yang di hasilkan dari metode kuesioner akan menjadi data primer dan yang dihasilkan dari teknik pengambilan data yang lain akan menjadi informasi tambahan.

\subsection{Identifikasi Dan Definisi Operasional Variabel}

Berikut definisi masing-masing variabel:

a. Kehandalan/Reliability (X1) adalah kemampuan memberikan layanan sesuai dengan yang dijanjikan. Indikatornya adalah memberikan layanan sesuai dengan SOP, kemampuan menawarkan produk dan jasa, dan memiliki wawasan luas.

b. Daya tanggap/Responsiveness (X2) indikatornya adalah memberikan salam pada pelanggan, tanggap memberikan informasi, dan cepat dalam pelayanan.

c. Jaminan/Assurance (X3) mencakup pengetahuan, kesopanan karyawan, dan kemampuan dalam membangkitkan kepercayaan serta keyakinan pelanggan. Indikatornya adalah keamanan yang terjaga, memberi pelayanan yang nyaman, tepat dan teliti serta memberikan penyelesaian masalah dengan tepat waktu.

d. Empati/Emphaty (X4) yaitu penyediaan pelayanan dalam memahami permasalahan, bertindak untuk kepentingan pelanggan, memberikan perhatian secara pribadi, mendengarkan complain, dan meminta maaf atas ketidaknyamanan.

e. Tampilan Fisik/Tangible (X5) yaitu meliputi fasilitas fisik, perlengkapan, penampilan. Indikatornya adalah menyediakan meja kerja, papan nama, alat tulis, ruang berAC, petugas berpenampilan rapi dan tata rias wajah dan rambut yang sangat diperhatikan kerpaihannya.

\subsection{Uji Instrumen}


Uji Instrumen dilakukan untuk melakukan pengukuran variabel yang akan diteliti sehingga untuk semua instrumen akan memiliki skala kur tersendiri. Dimana skala ukur menjadi kesepakatan yang akan dipakai sebagai parameter dalam menentukan interval yang akan diukur dan bersifat kuantitatif. Skala pengukuran sendiri menggunakan skala Likert sehingga yang digunakan mengukur berupa tingkah laku, argumen, dan pandangan seorang maupun kelompok mengenai dinamika sosial masyarakat yang akan digunakan menjadi indikator variabel. Berikut merupakan prosedur dalam pengukuran:

a. Pertanyaan umum akan dijawab oleh responden yang selanjutnya akan digunakan sebagai dasar pengukuran variabel.

b. Responden akan menjawab pertanyaan dengan jawaban dengan ketentuan yang sudah diatur.

c. Pemberian nilai untuk jawaban dengan skor tertentu.

\subsection{Uji Validitas}

Penelitian ini menggunakan teknik Korelasi Product Moment dimana teknik ini digunakan untuk mencari hubungan dan membuktikan hipotesis hubungan dua variabel atau lebih adalah sama berdasarkan rumus teknik Korelasi Product Moment (Widarjono, 2015).

\subsection{Uji Reliabilitas}

Jika alat ukur telah dinyatakan valid pada uji validitas maka alat ukur tersebut akan diuji reliabilitasnya (Supranto, 2004). Uji reliabilitas menghasilkan nilai 0,6 dihitung dengan menggunakan rumus Alpha Crobach.

\subsection{Pengolahan dan Analisis Data}

Pada tahap ini akan dilakukan pengumpulan, pengolahan dan penganalisaan data sesuai dengan data awal yang diperoleh. Model analisis yang akan digunakan dalam penelitian ini adalah model analisis faktor yang bertujuan untuk memilah data dengan cara mendata variabel asal kombinasi linier beberapa faktor sehingga faktor-faktor tersebut mampu mewakili keragaman variabel asal.

\subsection{Melakukan Analisis Faktor}

Tahap-tahap yang dilakukan dalam analisis faktor:

\begin{tabular}{|c|}
\hline Merumuskan Masalah \\
\hline Uji Interpedensi Variabel \\
\hline Bentuk Matriks Korelasi \\
\hline Menentukan Metode Analisis Faktor \\
\hline Melakukan Rotasi Faktor - Faktor \\
\hline
\end{tabular}




\section{HASIL DAN PEMBAHASAN}

\subsection{Hasil Penelitian}

Kuesioner disebar terhadap 30 kuesioner selanjutnya dilakukan uji validitas dan reliabilitas dari semua pertanyaan.

\section{a. Hasil Uji Validitas}

Corelasi Product Moment merupakan statistik uji yang digunakan untuk uji validitas, dimana $r_{\text {hitung }}>r_{\text {tabel }}$. Dari perhitungan diketahui dimensi faktor jaminan (assurance) atribut $\mathrm{X}_{3.4}$ data kualitas pelayanan memiliki nilai $r_{\text {hitung }}=0,507$ dan nilai $r_{\text {tabel }}=0,374$. Didapat bahwa $r_{\text {hitung }}>r_{\text {tabel }}$ sehingga atribut pertanyaan tersebut dinyatakan dapat digunakan pada analisis berikutnya karena sudah valid.

\section{b. Hasil Uji Reliabilitas}

Setelah data diuji kevalidannya dengan menggunakan korelasi product moment selanjutnya data tersebut diukur kereliabilitasannya dengan menggunakan teknik Cronbach's Alpha. Sebuah alat ukur dikatakan memiliki reliabilitas yang baik apabila memiliki nilai reliabilitas lebih dari 0,6 sedangkan pada perhitungan diketahui nilai Cronbach's Alpha yakni 0,796. Hal ini menunjukan bahwa nilai Cronbach's Alpha lebih besar dari 0,6 sehingga dapat dikatakan bahwa instrumen atau alat ukur telah reliabel.

\section{c. Analisis Faktor}

Dari data kuesinoner pada 27 atribut setelah dilakukan uji validitas dan reliabilitas data kuesioner terdapat 9 atribut yang tidak valid sehingga hanya 18 atribut yang dipakai pada perhitungan analisis faktor. Untuk mengetahui faktorfaktor yang mempengaruhi kualitas pelayanan perpustakaan SMAN 6 Tangerang Selatan maka dilakukan perhitungan analisis faktor.

\section{d. Uji Asumsi Analisis Faktor}

Variabel-variabel yang akan dianalisis harus saling berkorelasi dan data dari responden perlu di bentuk berupa matriks korelasi agar analisis faktor dapat digunakan (Fruchter, 1954). Matriks korelasi adalah matriks yang berisi koefisien korelasi dari setiap pasangan variabel untuk mendapat nilai keterkaitan antar variabel. Karena nilai keterkaitan ini selanjutnya dapat digunakan dalam pengujian untuk menentukan kemiripan dengan nilai korelasi yang didapat pada analisis faktor.

Untuk mengetahui apakah proses analisis faktor dapat digunakan dalam menginterpretasikan data yang ada dilakukan uji asumsi setelah matriks korelasi terbentuk. Uji asumsi melalui pengamatan dapat menggunakan ukuran kecukupan sampling (MSA), nilai Keiser-Meyer-Olkin (KMO), dan hasil uji Bartlett.

Pernyataan KMO terpenuhi karena berdasarkan nilai KMO hasil dari perhitungan SPSS adalah 0,541 sehingga nilai tersebut lebih besar dari 0,5 sebagai batasnya. Sedangkan nilai Bartlett Test of Sphericity juga memenuhi persyaratan uji signifikansi 0,005 atau 5\% karena signifikansinya 0,000 dan bernilai 347,845.

Nilai KMO diperoleh 0,618 yang berarti lebih besar dari 0,5 sementara untuk hasil Bartlett Test of Sphericity dengan signifikansi 0,05 diperoleh nilai sebesar 
0,000. Sehingga dari ketiga uji yang dilakukan telah memenuhi persyaratan yang ada untuk melakukan proses analisis faktor.

\section{e. Ekstraksi Faktor}

Untuk memperoleh faktor-faktor baru digunakan metode Principal Component Analysis dengan tujuan untuk mengeliminasi jumlah variabel menjadi komponen jumlah yang lebih sedikit dilakukan proses ekstraksi pada 11 atribut.

Pada perhitungan nilai PCA diketahui bahwa pelayanan yang diberikan petugas secara proaktif $\left(\mathrm{X}_{2.4}\right)$ pengaruh paling besar terhadap kepuasan pelanggan (Y) dengan presentase sebesar $\mathbf{0 , 6 9 1 . ~}$

Pada Rotated Component Matrix akan terlihat faktor-faktor yang akan masuk pada 4 faktor yang tebentuk. Besar korelasi antar variabel dengan faktor akan menjadi penentuan input variabel ke faktor, jika korelasi terbesar terdapat di komponen faktor 1 maka variabel tersebut masuk ke dalam faktor 1. Sehingga variabel-variabel yang masuk ke faktor 1, faktor 2, faktor 3, maupun faktor 4 akan didata untuk menjadi variabel.

Faktor 1:

1. Ketersediaan tempat baca $\left(\mathrm{X}_{5.7}\right)$

2. Kenyamanan ruangan $\left(\mathrm{X}_{5.4}\right)$

3. Kelengkapan tambahan $\mathrm{AC}$ atau kipas angin $\left(\mathrm{X}_{5.6}\right)$

4. Ruangan bagian luar dan dalam tertata dengan baik $\left(\mathrm{X}_{5.3}\right)$ Faktor 2:

1. Pelayanan yang diberikan petugas secara proaktif $\left(X_{2.4}\right)$

2. Keramahan petugas dalam melayani konsumen $\left(\mathrm{X}_{2.1}\right)$

3. Keprofesionalan petugas dalam melayani konsumen $\left(\mathrm{X}_{4.1}\right)$

Faktor 3:

1. Kesediaan/kesiapan petugas dalam memberikan pelayanan $\left(\mathrm{X}_{4.2}\right)$

2. Kelengkapan informasi yang disampaikan oleh petugas yang meliputi: informasi judul buku, banyaknya buku yang tersedia $\left(\mathrm{X}_{3.2}\right)$

Faktor 4:

1. Terdapat papan nama perpustakaan $\left(\mathrm{X}_{5.8}\right)$

2. Kejelasan informasi yang disampaikan oleh petugas perpustakaan $\left(\mathrm{X}_{3.1}\right)$

Dihasilkan ke-4 faktor memiliki korelasi yang cukup kuat $(>0,5)$ dan tepat untuk mewakili ke-11 variabel independen sebelumnya.

\subsection{Pembahasan}

Pada Rotated Component Matrix dapat dilihat pengelompokkan variabel yang masuk ke faktor 1, faktor 2, faktor 3, maupun faktor 4. Nilai koefisien korelasi terbesar antara variabel dengan faktor menjadi penentu input variabel ke faktor tertentu (Wei, 1990). Berikut ini penentuan variabel-variabel yang akan di masukkan ke faktor 1, faktor 2, faktor 3, dan faktor 4 berdasarkan hasil output:

a. Keramahan petugas dalam melayani konsumen (X2.1), Variabel ini masuk faktor (X2), karena nilai terbesar antara koefisien korelasi dengan faktor ada di faktor 2, yaitu sebesar $\mathbf{0 , 7 2 5}$. 
b. Pelayanan yang diberikan petugas secara proaktif (X2.4), Variabel ini masuk faktor (X2), karena nilai terbesar antara koefisien korelasi dengan faktor ada di faktor 2, yaitu sebesar $\mathbf{0 , 8 2 0}$.

c. Kejelasan informasi yang disampaikan oleh petugas perpustakaan (X3.1), Variabel ini masuk faktor (X4), karena nilai terbesar antara koefisien korelasi dengan faktor ada di faktor 4, yaitu sebesar $\mathbf{0 , 6 1 4}$.

d. Kelengkapan informasi yang disampaikan oleh petugas oleh petugas meliputi informasi judul buku dan banyaknya buku yang tersedia (X3.2) Variabel ini masuk faktor (X3), karena nilai terbesar antara koefisien korelasi dengan faktor ada di faktor 3, yaitu sebesar $\mathbf{0 , 7 4 9}$.

e. Keprofesionalan petugas dalam melayani konsumen (X4.1), Variabel ini masuk faktor (X2), karena nilai terbesar antara koefisien korelasi dengan faktor ada di faktor 2, yaitu sebesar $\mathbf{0 , 5 5 1}$.

f. Kesediaan/kesiapan petugas dalam memberikan pelayanan (X4.2), Variabel ini masuk faktor (X3), karena nilai terbesar antara koefisien korelasi dengan faktor ada di faktor 3, yaitu sebesar $\mathbf{0 , 7 7 5}$.

g. Ruangan bagian luar dan dalam tertata dengan baik (X5.3), Variabel ini masuk faktor (X1), karena nilai terbesar antara koefisien korelasi dengan faktor ada di faktor 1 , yaitu sebesar $\mathbf{0 , 6 2 2}$.

h. Kenyamanan ruangan, apakah sudah memadai dan dapat merasa nyaman (X5.4) Variabel ini masuk faktor (X1), karena nilai terbesar antara koefisien korelasi dengan faktor ada di faktor 1, yaitu sebesar $\mathbf{0 , 7 4 2}$.

i. Kelengkapan tambahan AC atau Kipas Angin (X5.6), Variabel ini masuk faktor (X1), karena nilai terbesar antara koefisien korelasi dengan faktor ada di faktor 1 , yaitu sebesar $\mathbf{0 , 7 0 3 .}$

j. Ketersediaan tempat baca (X5.7), Variabel ini masuk faktor (X1), karena nilai terbesar antara koefisien korelasi dengan faktor ada di faktor 1, yaitu sebesar $\mathbf{0 , 7 7 4}$.

k. Terdapat papan nama perpustakaan (X5.8), Variabel ini masuk faktor (X4), karena nilai terbesar antara koefisien korelasi dengan faktor ada di faktor 4 , yaitu sebesar 0,736.

\subsection{Interpretasi Faktor}

Dari 5 faktor yang diteliti dengan menggunakan proses factoring dapat direduksi menjadi 4 faktor, sebagai berikut:

a. Faktor Tangible/Berwujud (X1) terdiri atas variabel independen, yaitu: Ruangan bagian luar dan dalam tertata dengan baik (X5.3), Kenyamanan ruangan (X5.4), Kelengkapan tambahan tambahan AC atau Kipas Angin (X5.6), Ketersediaan ruang baca (X5.7). Karena pada tabel 4.13 Component Transformation Matrix, korelasi antar variabel X5.3, X5.4, X5.6, X5.7 dengan faktor X1 adalah positif sebesar 0,725, maka faktor tersebut berpengaruh untuk kepuasan konsumen terhadap kualitas pelayanan perpustakaan SMAN 6 Kota Tangerang selatan

b. Faktor Reliability/Keandalan (X2) terdiri atas variabel independen, yaitu: Pelayanan yang diberikan petugas secara proaktif (X2.4), Keramahan petugas dalam melayani konsumen (X2.1), Keprofesionalan petugas dalam melayani konsumen (X4.1). Karena pada tabel 4.13 Component Transformation Matrix, korelasi antar variabel 
$\mathrm{X} 2.4, \mathrm{X} 2.1, \mathrm{X} 4.1$ dengan faktor X2 adalah positif sebesar 0,502, maka faktor tersebut berpengaruh untuk kepuasan konsumen terhadap kualitas pelayanan perpustakaan SMAN 6 Kota Tangerang selatan

c. Faktor Empathy/Empati (X3) terdiri atas variabel independen, yaitu: Kesediaan/kesiapan petugas dalam memberikan pelayanan (X4.2), Kelengkapan informasi yang disampaikan oleh petugas (X3.2). Karena pada tabel 4.13 Component Transformation Matrix, korelasi antar variabel X4.2, X3.2 dengan faktor $\mathrm{X} 3$ adalah positif sebesar 0,618, maka faktor tersebut berpengaruh untuk kepuasan konsumen terhadap kualitas pelayanan perpustakaan SMAN 6 Kota Tangerang Selatan

d. Faktor Assurance/Jaminan (X4) terdiri atas variabel independen, yaitu: Terdapat papan nama perpustakaan (X5.8), Kejelasan informasi yang disampaikan oleh petugas (X3.1). Karena pada tabel 4.13 Component Transformation Matrix, korelasi antar variabel X5.8, X3.1 dengan faktor X4 adalah positif sebesar 0,850, maka faktor tersebut berpengaruh untuk kepuasan konsumen terhadap kualitas pelayanan perpustakaan SMAN 6 Kota Tangerang Selatan.

\section{SIMPULAN}

Berdasarkan dari hasil perhitungan maka dapat disimpulkan bahwa dengan metode analisis faktor, terbentuk 4 faktor yang mempengaruhi tingkat kepuasan pelanggan terhadap kualitas pelayanan perpustakaan SMAN 6 Kota Tangerang Selatan dari 11 variabel yang telah direduksi yang mempunyai korelasi yang tinggi di atas 0,5 . Adapun faktor tersebut yaitu: faktor berwujud/Tangible $\left(\mathrm{X}_{1}\right)$ dengan nilai korelasi sebesar $\mathbf{0 , 7 2 5}$, keandalan/Reliability $\left(\mathrm{X}_{2}\right)$ nilai korelasinya $\mathbf{0 , 5 0 2}$, faktor empati/Emphaty $\left(\mathrm{X}_{3}\right)$ nilai korelasinya $\mathbf{0 , 6 1 8}$, dan jaminan/Assurance $\left(\mathrm{X}_{4}\right)$ nilai korelasinya sebesar $\mathbf{0 , 8 5 0}$.

Dari faktor-faktor yang sudah diteliti tersebut, faktor jaminan/assurance $\left(\mathrm{X}_{4}\right)$ merupakan faktor kualitas pelayanan yang paling berpengaruh terhadap kepuasan konsumen dengan nilai korelasi sebesar $\mathbf{0 , 8 5 0}$. Terdiri dari variabel dengan terdapat papan nama perpustakaan sebagai penunjuk keberadaan perpustakaan $\left(\mathrm{X}_{5.8}\right)$ dan kejelasan informasi yang disampaikan oleh petugas $\left(\mathrm{X}_{3.1}\right)$.

\section{DAFTAR PUSTAKA}

Wei, William W. S. (1990). Time Series Analysis: Univariate and Multivariate Methods. USA: Addison Wasley.

Bungin, Burhan. (2013). Metodologi Penelitian Sosial dan Ekonomi, Edisi Pertama. Jakarta: Prenadamedia Group.

Fruchter, B. (1954). Induction to Factor Analysis. New York: D. Van Nostrand Company Ltd.

Gunawan, Imam. (2016). Pengantar Statistika Inferensial. Jakarta: PT. Raja Grafindo Persada.

Nazir, Moh. (2016). Metode Penelitian. Bogor: Ghalia Indonesia

Parasuraman, A. dkk. (1988). Servqual: A Multiple - Item Scale for Measuring

Consumer Perception of Service Quality. Journal of Retailing: Vol.64. pp 12-40.

Sangaji Mamang. (2015). Metode Penelitian, Yogyakarta, ANDI.

Sudarno, et. al. (2015). “Analisis Kualitas Pelayanan dan Pengendalian Kualitas Jasa 
Berdasarkan Persepsi Pengunjung". Jurnal Media Statistik. 4(1): 33-34.

Sugiyono. (2016). Metode Penelitian Kuantitatif, Kualitatif dan R\&D. Bandung: Alfabeta.

Supranto, J. (2004). Analisis multivariat arti dan isi. Jakarta: Rineka Cipta.

Widarjono, Agus. (2015). Analisis Multivariat Terapan. Yogyakarta: UPP STIM YKPN.

Yeri Sutopo. (2017). Statistik Inferensial. Yogyakarta: ANDI. 